Case Study

\title{
Anomaly Detection of Grid Connected Photovoltaic System Based on Degradation Rate: A Case Study in Malaysia
}

\author{
Mohamad Zhafran Hussin ${ }^{1 *}$, Nor Diyana Md Sin ${ }^{1}$, Hedzlin Zainuddin², Ahmad \\ Maliki Omar ${ }^{3}$ and Sulaiman Shaari ${ }^{2}$
}

${ }^{1}$ Faculty of Electrical Engineering, Universiti Teknologi MARA (UiTM) Cawangan Johor, Kampus Pasir Gudang, 81750 Masai, Johor, Malaysia

${ }^{2}$ Faculty of Applied Sciences, Universiti Teknologi MARA (UiTM) Shah Alam, 41450 Shah Alam, Selangor, Malaysia

${ }^{3}$ Faculty of Electrical Engineering, Universiti Teknologi MARA (UiTM) Shah Alam, 41450 Shah Alam, Selangor, Malaysia

\begin{abstract}
This paper presents the characterization and performance of six-year field data for two different systems of PV module technologies from the rooftop grid-connected system installed at Universiti Teknologi MARA (UiTM) Shah Alam. Two different PV module technologies are used as case studies to establish a method of anomaly detection on the system performance. The selected parameters such as string voltage, string current and AC power output are used in the analysis, while solar irradiance and module temperature are used as a reference basis. Based on the results obtained, both systems having degradation rates differently. System A had shown stable performance before it degraded by $16.09 \%$ after the 4th-year of operation, whereas system B continuously decreased by $39.35 \%$

ARTICLE INFO

Article history:

Received: 7 June 2021

Accepted: 22 August 2021

Published: 28 October 2021

DOI: https://doi.org/10.47836/pjst.29.4.48

E-mail addresses:

mzhafran@uitm.edu.my (Mohamad Zhafran Hussin)

diyana0366@uitm.edu.my (Nor Diyana Md Sin)

hedz1506@uitm.edu.my (Hedzlin Zainuddin)

maliki_omar@uitm.edu.my (Ahmad Maliki Omar)

solarman@uitm.edu.my (Sulaiman Shaari)

*Corresponding author

during the monitored period. However, the string current of system A degraded up to $4.4 \%$ and, interestingly, no degradation for the string voltage. In contrast, system B has experienced a degradation of the string current by about $21.6 \%$, whereas the string voltage was around $16.16 \%$. Therefore, the string current and string voltage could identify the cause of the degradation rate of AC power. This analysis could be used to
\end{abstract}


diagnose and identify the sources and causes of power degradation of grid-connected PV systems so that further action could be taken.

Keywords: Degradation, grid-connected, photovoltaic system, string current, string voltage

\section{INTRODUCTION}

The Government of Malaysia is committed to achieving the $20 \%$ target for the Renewable Energy (RE) sector in the national generation capacity mix by 2025 . The preliminary Renewable Energy Transition Roadmap (RETR) 2035 developed by the Sustainable Energy Development Authority (SEDA) (http://www.seda.gov.my/) has projected that solar PV will contribute more than half of RE's target capacity by 2025 based on two key factors due to higher average solar irradiation and continuing decline trend in the price of solar PV technology (Velautham et al., 2019). As of 2019, the installed capacity of the solar PV installation is around 882.02 MW (Vaka et al., 2020). During the early stage of the Malaysia Building Integrated Photovoltaic (MBIPV) program, the PV cost index is approximately MYR32.00/Wp (Hussin et al., 2012). Almost all components in the gridconnected photovoltaic (GCPV) system were imported from European countries. However, once solar products from China were introduced in the Malaysia market around 2017, it witnessed a significant drop in PV cost index until 2019, where the average present cost is roughly MYR2.91 to MYR5.58/Wp for residential Building Integrated Photovoltaic (BIPV) until small centralised PV applications (Velautham et al., 2019).

At the end of 2011, Malaysia launched a Feed-in Tariff (FiT) scheme through The Renewable Energy Act 2011. The scheme obliges the Distribution Licensees (DLs) to buy the electricity produced from grid-connected renewable energy for 21 year period for solar PV and mini-hydro and a 16-years for biomass and biogas. However, by 2016, the FiT scheme will no longer be offered for solar PV quota allocation and replaced by a new Net Energy Metering programme (NEM1.0). NEM1.0 permits consumers to consume the energy generated by solar PV systems. Any surplus will be resold to the utility grid or distribution licensee (TNB/SESB) at the prevailing Displaced Cost prescribed by the Energy Commission instead of selling all harvested energy as in the FiT scheme. However, this mechanism does not help reduce consumer utility bills, especially for small-size residential.

As a result, the NEM2.0 scheme was updated to replace the previous scheme to overcome the drawbacks by making it a "one-to-one" energy offset mechanism instead of the previous net billing mechanism implemented from 2016 to 2018. Recently, NEM3.0 was introduced in December 2020 once NEM2.0 has been fully subscribed and will be effective from 2021 to 2023 (SEDA). Most GCPV system owners are only interested in monthly energy generation, which reflects their electricity bills. They are only interested in knowing in detail if their monthly electricity bill is not up to their expectations, especially 
when they are engaged with the NEM scheme. If any problems occurred in their system, such as shading, solar panel defects, i.e., hotspots, micro-cracks, light-induced degradation (LID) or potential-induced degradation (PID) effects throughout the contract (Fouad et al., 2017), the return-on-investment (ROI) will not be achievable where most systems usually take 4 to 7 years if using FiT scheme (Husain et al., 2020; Yatim et al., 2014), and 10 to 22 years if using NEM1.0 scheme (Husain et al., 2020; Yatim et al., 2017) to get their investment back. For NEM2.0 and NEM3.0, ROI is expected to achieve in 6 to 7 years. Today, the PV cost index is around MYR4 to MYR 5/Wp for residential.

In harvesting free energy from the sun, some limitations contribute to power loss, such as geographical locations, climates and the reliability of BOS components such as PV module technology and inverter. Thus, generally, the power loss in the GCPV system could be divided into two categories, namely sub-system power loss and PV modules power loss. Sub-system power loss includes power losses in cables and inverters. The second category is the power loss within the PV module can be further classified into controllable and uncontrollable power loss. In a controllable power loss, the effect of heat, partial shading, faulty bypass diode and soiling are manageable. However, uncontrollable power loss due to the presence of snail trails, crack, or micro-crack, potential-induced degradation (PID), light-induced degradation (LID), ageing, decolourisation and hot spot are not manageable (Hussin et al., 2015; Islam et al., 2018; Jumien et al., 2015; Muhammad et al., 2017).

The reliability of the GCPV system is one of the major factors that determine the profitability of PV projects because the performance of the PV system has a huge impact on energy production. Thus, it is essential to evaluate the performance of the GCPV system continuously. Thus, the PV system integrators and owners could minimise the risks and losses over long-term investments. Many stakeholders, especially PV manufacturers, are interested to know their on-site product performance. Degradation of PV modules or systems can occur for many reasons. Most of the power warranty by PV manufacturers is 25-year for mono facial and 30-year for bi-facial double-glass PV modules. Currently, the lack of knowledge sharing, particularly under warm and humid climates related to degradation issues, becomes more pronounced when the owners are interested in their long-term risk investments, particularly in the reliability and longevity of installed systems (Halwachs et al., 2019; Köntges et al., 2017).

According to an extensive review by Phinikarides et al. (2014), the average degradation rate for mono-crystalline was $0.89 \%$ /year, poly-crystalline was $0.81 \%$ /year, while a-Si, CIGS, CdTe around 1.34\%/year, 1.86\%/year, 1.70\%/year, and other thin-film technologies were found to be $2.24 \%$ year. In the context of degradation rates, several researchers have investigated the outdoor performance of various PV module technologies at different locations under tropical and sub-tropical climates such as Thailand. The overall degradation rate is between $0.5 \%$ to $4.9 \%$ / year, and for poly-crystalline (p-Si) is around $0.5 \%$ to $1.2 \%$ / 
year (Limmanee et al., 2017; Limmanee et al., 2016). Such a trend is also reported in many other countries that use crystalline silicon (c-Si) types. For example, in Indonesia, Singapore, Ghana, Algeria and India, the PV degradation rate is equal to $1.6 \% /$ year in Indonesia (Kunaifi et al., 2020), 0.8\% to 1.0\%/year in Singapore (Ye et al., 2014), 1.3\%/ year in Ghana (Quansah, 2017), 0.76\%/year in Algeria (Dahmoun et al., 2021) and 1.33\%/ year in India (Dubey et al., 2017). However, there is limited published literature on the long-term reliability of PV modules installed in the tropical region. Previous collections in the context of degradation studies in the tropics are primarily based on data collected under four-year, except in Ghana around 19 years.

From a global point of view, the average degradation rate varies from $0.89 \%$ to $6 \%$ / year, which depends on the types of PV module technology, geographical location and climate. If it exceeds the average value, it needs to be investigated further as it may be related to the uncontrolled power loss. Several case studies related to the uncontrollable power loss used three performance metrics: energy yield, performance ratio, and indoor power, to estimate the annual degradation rates for six types of c-Si PV modules (Ishii $\&$ Masuda, 2017). The authors have concluded that a small degradation of the newly PV modules was observed between $0.1 \%$ year and $0.4 \%$ year over three years of operation.

However, poly-crystalline and mono-crystalline declined by $2 \%$ due to light-induced degradation (LID) after initial exposure to sunlight. In comparison, the sc-Si heterojunction (SJH) and interdigitated back contact (IBC) sc-Si clearly showed the annual degradation of PR decreased by approximately $1.4 \%$ and $0.5 \%$ year. In addition, the authors found that the IBC sc-Si experienced an open-circuit voltage which might cause by potentialinduced degradation (PID) symptoms. Other issues were found from field-testing under the Malaysian environment. For example, nine-year-old PV modules using poly-crystalline suffered from PID, where it decreased by $42 \%$ due to on-site negative voltage stress and $17 \%$ for normal field ageing. Furthermore, all tested PV modules revealed several defects such as cracked propagation accelerating the PID by high voltage stress (Islam et al., 2018). Recently, several researchers used various methods to determine the rate of accuracy and identify the early stage of degradation, which such methods from statistical analysis methods (Malvoni et al., 2020; Phinikarides et al., 2014; Saleheen et al., 2021), commercial software tools (Malvoni et al., 2017; Okello et al., 2015), PV performance metrics or IV characterisation (Dahmoun et al., 2021; Kazem et al., 2020; Roumpakias \& Stamatelos, 2019) and other visual or defect issues (Bansal et al., 2021; Lillo-Sánchez et al., 2021).

It is essential to know the sources of power degradation rates to help the PV industry decide on the manufacturing process, investment terms and warranties. Besides that, this can also help the user understand the power degradation factor in the actual situation. Although many existing developed techniques in PV systems are available in the market, most of the methods are highly technical and too complicated for ordinary users. Therefore, 
it is essential to develop an analysis of degradation that is understandable by all users. The purpose of this paper is to introduce a new technique for determining the annual degradation of grid-connected photovoltaic (GCPV) systems. As a case study, two grid-connected systems are investigated, operating since 2012 in Malaysia (tropical rainforest climate, Af).

\section{MATERIALS AND METHODS}

This case study is based on an earlier model of PV modules installed in 2012 at Green Energy Research (GERC), UiTM Shah Alam, Selangor Darul Ehsan. There are two GCPV systems investigated with different technologies of PV modules installed, namely System A and System B. The electrical data were taken from a dedicated data logger from 2012 to 2017 with logging time at an interval of 5-minute. The characteristics of both systems as tabulated in Table 1.

Table 1

System characteristics of system $A$ and system $B$

\begin{tabular}{|c|c|c|}
\hline Description & System A & System B \\
\hline System & Grid-connected & Grid-connected \\
\hline Nominal Power (kWp) & 5.405 & 10 \\
\hline Mounting & Retrofitted & Retrofitted \\
\hline PV module technology & Polycrystalline (pc-Si) & Monocrystalline (mc-Si) \\
\hline Array configuration & $1 \mathrm{p} \times 11 \mathrm{~s} / 1 \mathrm{p} \times 12 \mathrm{~s}$ & $2 p \times 20 s$ \\
\hline Inverter & SB5000TL & STP8000TL \\
\hline
\end{tabular}

The electrical parameters used are alternating current (AC) power, string voltage, string current, the plane of array solar irradiance and module temperature. One-month data starting from the date of commissioning with one-year gaps are used in this analysis.

The AC power, DC voltage and DC current are normalised to its array capacity rating. Then, the predicted values are calculated using the following Equations 1-3:

$$
P_{\text {ac_predict }}=P_{\text {array_stc }} \times \frac{G}{1000} \times K_{\text {temp }} \times K_{\text {age }} \times K_{c}
$$

Where $P_{\text {ac_predict }}$ is the predicted value for AC power output, $P_{\text {array_stc }}$ is PV array capacity, $G$ is plane of array solar irradiance, $K_{\text {temp }}$ is a de-rating factor due to temperature, $K_{a g e}$ is an ageing factor, and $K_{c}$ is a constant derate factor due to cable loss, inverter, shading, mismatch and soiling. Therefore, from Equation 1, AC power output is very much influenced by solar irradiance. $V_{d c}$ significantly influences the $K_{\text {temp }}$ besides small 
influence by $K_{m m_{-} v}$, voltage module mismatch factor as given in Equation 2.

$$
V_{d c_{-} \text {predict }}=V_{\text {string }} \times K_{\text {temp }} \times K_{m m_{\_} v}
$$

In addition, $I_{d c}$ during operating conditions is directly affected mainly by solar irradiance, G despite other factors, namely $K_{m m_{-} i}$, current module mismatch, temperature, soling and shading, as illustrated in Equation 3.

$$
I_{d c_{-} \text {predict }}=I_{m p \_s_{\text {stc }}} \times \frac{G}{1000} \times K_{m_{-} i} \times K_{\text {temp_i }} \times K_{\text {soiling }} \times K_{\text {shading }}
$$

The monitoring standard IEC61724 was referred to calculate the final yield and performance ratio. For final yield, $Y_{f}$ is defined as the annual, monthly, or daily AC energy output in $\mathrm{kWh}, E_{a c}$ of the PV system per installed PV array power, $P_{o}$ as shown in Equation 4.

$$
Y_{f}=\frac{E_{a c}}{P_{o}}
$$

Performance ratio (PR) is typically used to assess the installation quality of PV systems. The reference yield $Y_{r}$ is the total amount of in-plane solar irradiation $\mathrm{H}\left(\mathrm{kWh} / \mathrm{m}^{2}\right)$, divided by reference irradiance, $G_{r e f}\left(1 \mathrm{~kW} \cdot \mathrm{m}^{-2}\right)$ and can be calculated as equated in Equation 5.

$$
\mathrm{PR}=\frac{Y_{f}}{Y_{r}}
$$

Thus, those five equations are used as a reference in this analysis. This study's selected parameters for degradation investigation are AC power, string voltage, string current, final yield and performance ratio.

\section{RESULTS AND DISCUSSIONS}

The PV modules are evaluated to address the degradation rate after six years of operation. Finally, the measurement results are presented in this case study.

\section{AC Power Output}

For system A, there is no significant degradation of AC power in the second year of operation. However, significant power degradation happened after the fourth year (2015) onwards, as shown in Figure 1(a). After that, the AC power appears to be stabilised at $16.09 \%$ in the fifth and the sixth year. However, system B shows continuous degradation of AC power output every year, as shown in Figure 1(b). This trend demonstrates anomaly conditions. It can be seen from Table 2 . The AC power is dramatically degraded by $39.35 \%$ over six years of operation. For comparative purposes, analysis at solar irradiance 1000 $\mathrm{W} . \mathrm{m}^{-2}$ is used as a reference. 


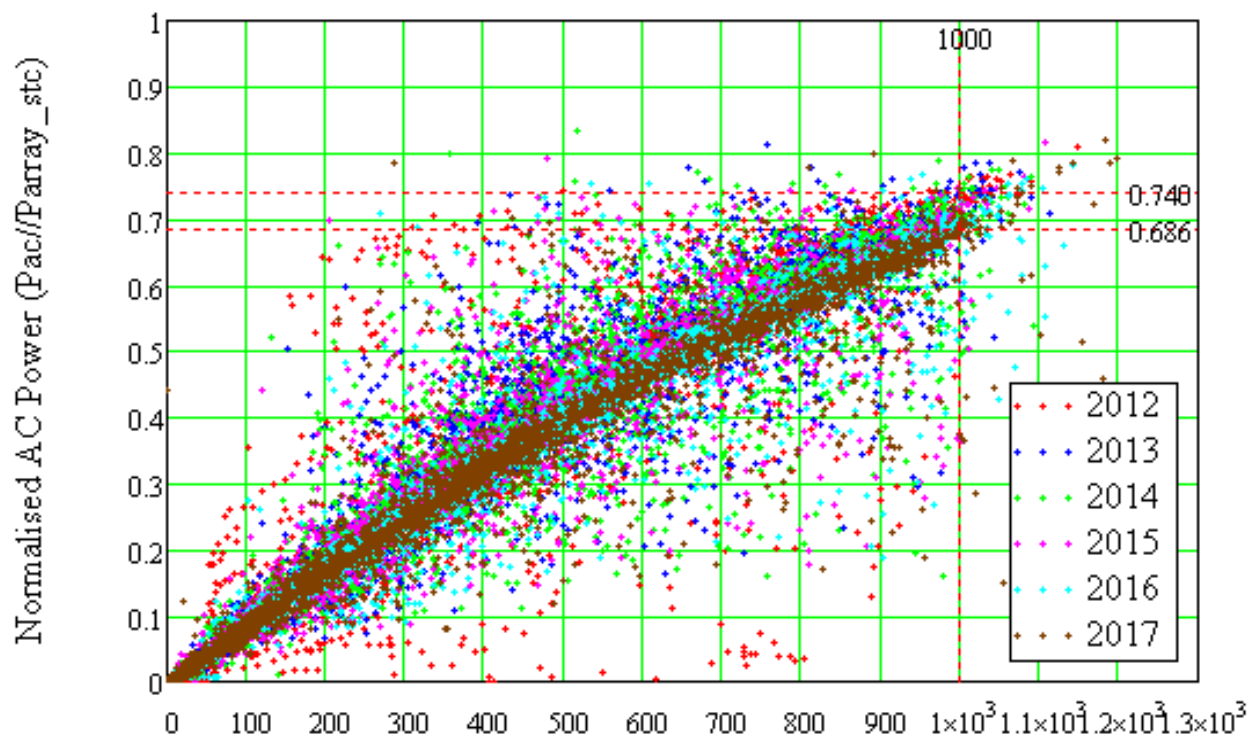

Solar Irradiance (W/Sq.m)

(a)

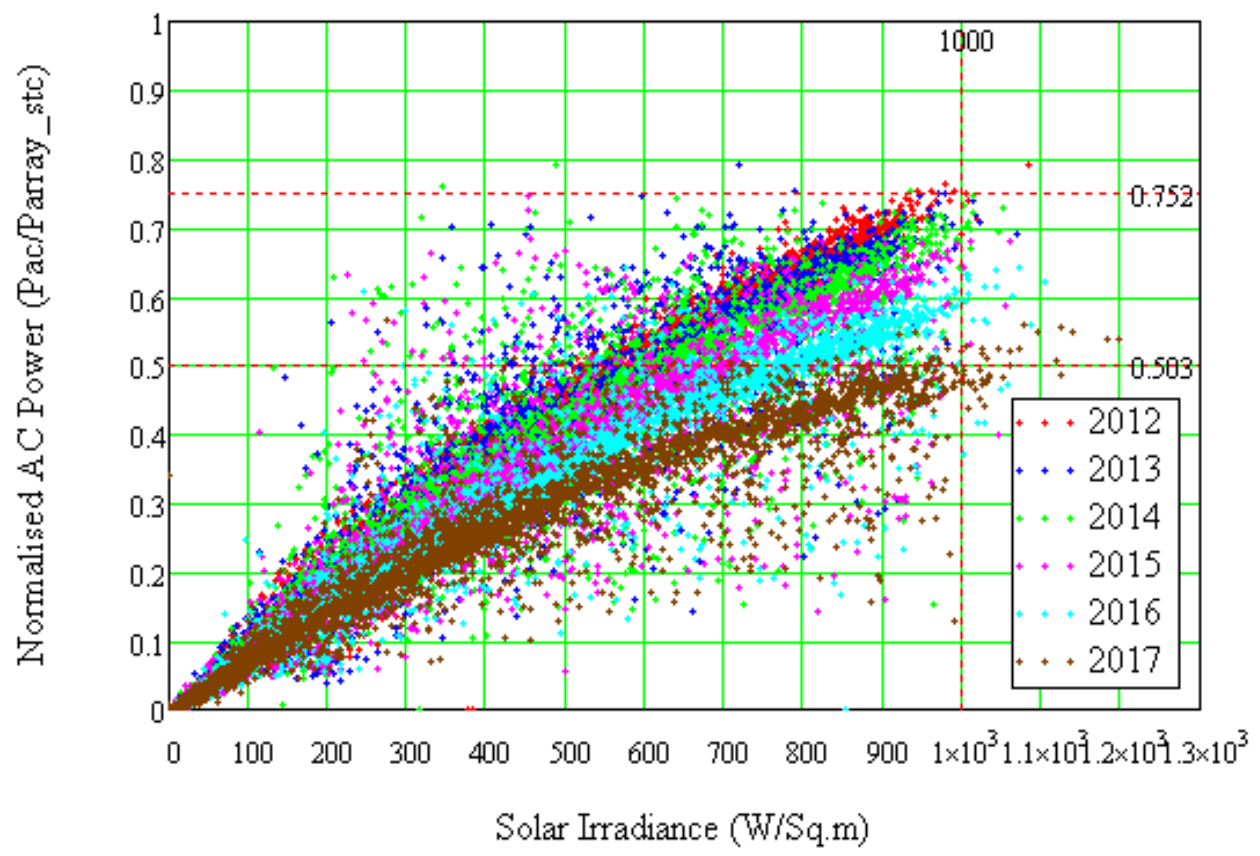

(b)

Figure 1. Degradation of AC power with solar irradiance (a) System A (b) System B 
The amount of AC power output degradation with solar irradiance during six years of operation is tabulated in Figure 1.

Table 2

Comparative degradation of $A C$ power

\begin{tabular}{lcc}
\hline Year & $\begin{array}{c}\text { System A } \\
\text { AC power drop, at } \mathrm{G}=1,000 \\
\mathrm{~W} / \mathrm{m}^{2}(\%)\end{array}$ & $\begin{array}{c}\text { System B } \\
\text { AC power drop at } \mathrm{G}=1,000 \\
\mathrm{~W} / \mathrm{m}^{2}(\%)\end{array}$ \\
\hline $2012\left(1^{\text {st }}\right.$ year $)$ & 0.0 & 0.0 \\
$2013\left(2^{\text {nd }}\right.$ year $)$ & 0.0 & 5.66 \\
$2014\left(3^{\text {rd }}\right.$ year $)$ & 1.03 & 8.42 \\
$2015\left(4^{\text {th }}\right.$ year $)$ & 13.34 & 19.14 \\
$2016\left(5^{\text {th }}\right.$ year $)$ & 16.09 & 28.57 \\
$2017\left(6^{\text {th }}\right.$ year $)$ & 16.09 & 39.35 \\
\hline
\end{tabular}

\section{String Current}

The degradation of string current with solar irradiance during six years of operation is shown in Figure 2. The degradation of string current for both systems contributes to power loss. The percentage of yearly string current degradation for system A and system B is tabulated in Table 3. For system A, it was found that there was no string current degradation for the first three years. However, after the fourth year, it was degraded by $3.3 \%$ to $4.4 \%$, as shown in Figure 2(a). It is possibly due to natural ageing and soiling effect (Jamil et al., 2020).

On the other hand, system B demonstrated distinctive string current degradation, which is doubled every year consecutively until it reached $21.6 \%$, as illustrated in Figure 2(b). It is possibly due to PV module failure, which needs further investigation, besides natural ageing and soil factors. Soil factors influence the penetration of sunlight into the PV module. Less string current can be seen because the PV modules installed in this area suffer from pollution problems such as new factories and construction sites. Thus, the modules need to be cleaned periodically even though both systems are exposed to natural cleaning via rainwater. 


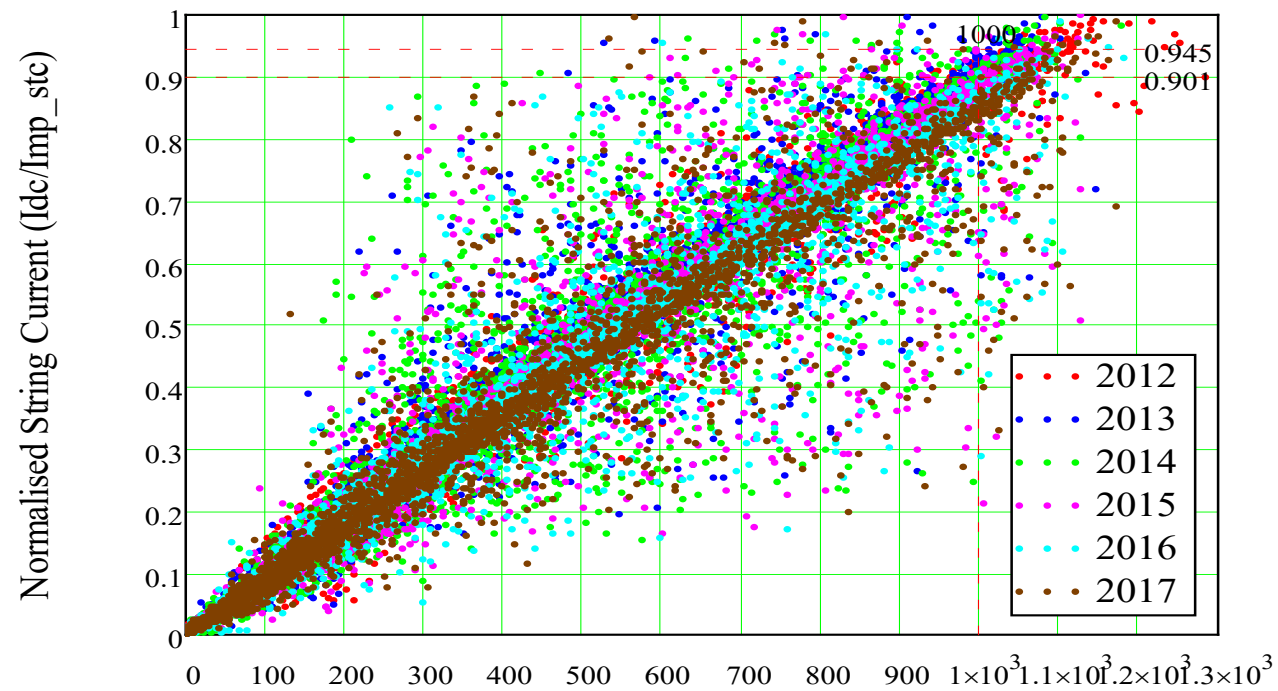

Solar Irradiance (W/Sq.m)

(a)

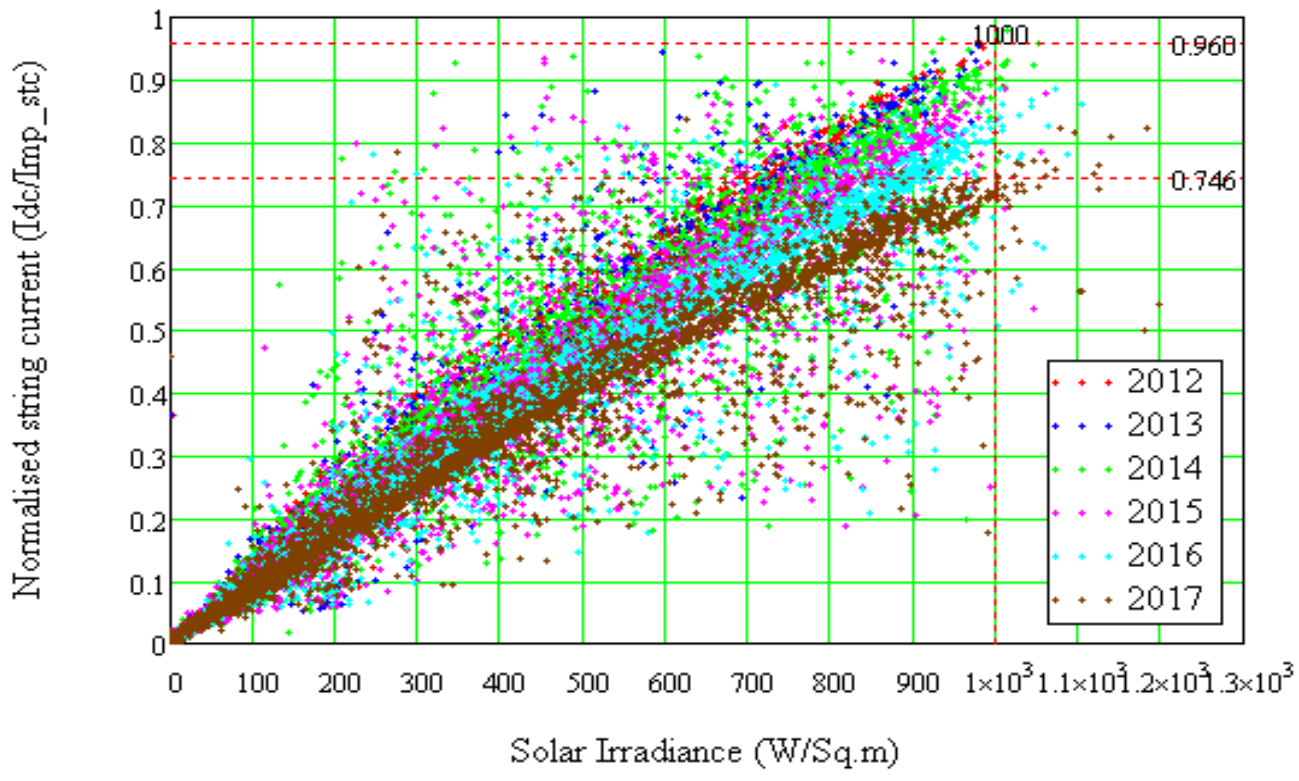

(b)

Figure 2. Degradation of string current with solar irradiance (a) System A (b) System B. 
Table 3

Comparative degradation of string current

\begin{tabular}{|c|c|c|}
\hline Year & $\begin{array}{c}\text { System A } \\
\text { String current degradation at } \\
\mathrm{G}=1,000 \mathrm{~W} / \mathrm{m}^{2}(\%)\end{array}$ & $\begin{array}{c}\text { System B } \\
\% \text { String current degradation at } \\
\mathrm{G}=1,000 \mathrm{~W} / \mathrm{m}^{2}(\%)\end{array}$ \\
\hline $2012\left(1^{\text {st }}\right.$ year $)$ & 0 & 0 \\
\hline 2013 ( $2^{\text {nd }}$ year $)$ & 0 & 0 \\
\hline 2014 ( $3^{\text {rd }}$ year $)$ & 0 & 3.1 \\
\hline 2015 (4 $4^{\text {th }}$ year $)$ & 3.3 & 7.2 \\
\hline $2016\left(5^{\text {th }}\right.$ year $)$ & 4.4 & 13.4 \\
\hline 2017 ( $6^{\text {th }}$ year $)$ & 4.4 & 21.6 \\
\hline
\end{tabular}

\section{String Voltage}

The degradation of string voltage with module temperature during six years of operation is illustrated in Figure 3. From Table 4, system A observed an insignificant drop of string voltage, whereas system B displayed significant degradation of string voltage in the fourth year, which is $13.27 \%$. Thus, the degradation of $\mathrm{AC}$ power of system $\mathrm{A}$ is not due to string voltage. However, the voltage degradation for system $\mathrm{B}$ continued to decline until it reached $16.6 \%$ at the end of six years of operation in 2017. It clearly shows that the degradation of AC power of system B contributes to the degradation of string voltage. It is not the symptom of soiling or ageing effect, but possible indications of potential-induced degradation (PID) that occurs when PV modules operate at high voltages, combined with warm and humid weather conditions (Islam et al., 2018). The potential causes of PID are mostly due to a combination of factors from high voltage, high temperature and high humidity. This finding requires further investigation to establish its actual cause.

Table 4

Comparative degradation of string voltage

\begin{tabular}{lcc}
\hline Year & $\begin{array}{c}\text { System A } \\
\text { String voltage drop, } \\
\text { at } T_{m}=65^{\circ} \mathrm{C}(\%)\end{array}$ & $\begin{array}{c}\text { System B } \\
\text { String voltage drop, } \\
\text { at } T_{m}=65^{\circ} \mathrm{C}(\%)\end{array}$ \\
\hline $2012\left(1^{\text {st }}\right.$ year $)$ & 0.0 & 0.0 \\
$2013\left(2^{\text {nd }}\right.$ year $)$ & 0.0 & 0.0 \\
$2014\left(3^{\text {rd }}\right.$ year $)$ & 0.0 & 0.0 \\
$2015\left(4^{\text {th }}\right.$ year $)$ & 0.0 & 13.27 \\
$2016\left(5^{\text {th }}\right.$ year $)$ & 0.0 & 14.04 \\
$2017\left(6^{\text {th }}\right.$ year $)$ & 0.0 & 16.16 \\
\hline
\end{tabular}




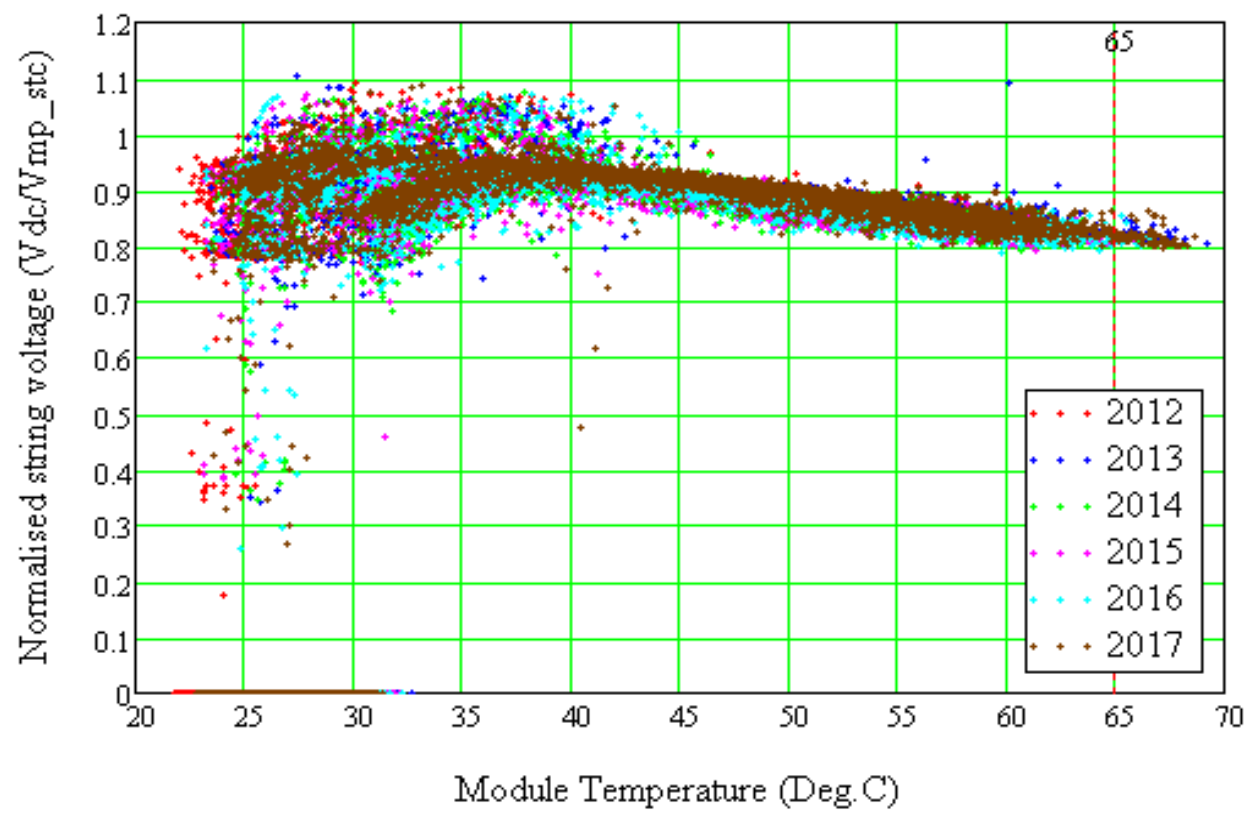

(a)

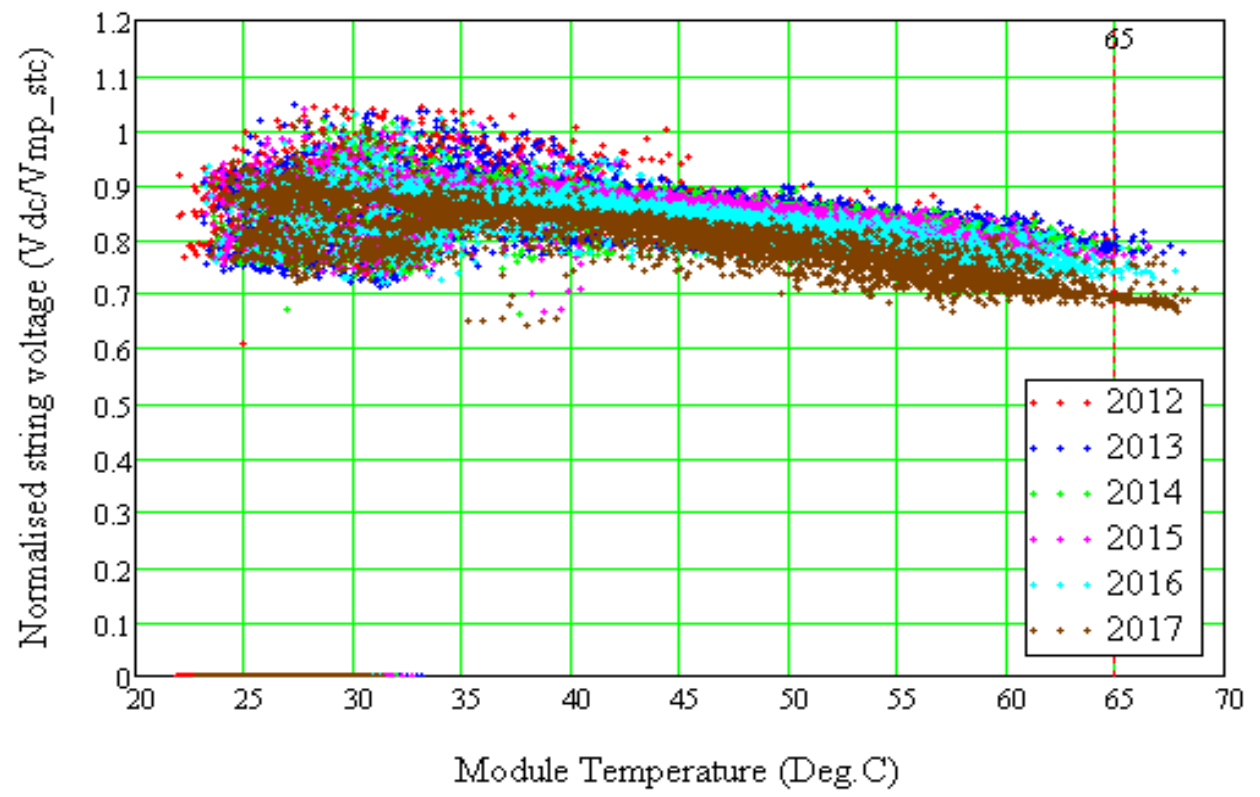

(b)

Figure 3. Degradation of string voltage with module temperature (a) System A (b) System B 


\section{Final Yield}

The monthly final yield $Y_{f_{-} m}$ for both systems during six years of operation is shown in Figure 4. The bar graph shows system A's average final yield is more than $100 \mathrm{kWh} /$ kWp (benchmark $Y_{f}$ used for Malaysia GCPV system [SEDA, 2016]) over its six years of operation. Thus, their excellent performance can be observed even though system A exhibits a fluctuation in yield generation. Meanwhile, system B keeps on dropping after the second year, where the overall final yield is less than $100 \mathrm{kWh} / \mathrm{kWp}$ during the monitoring period.

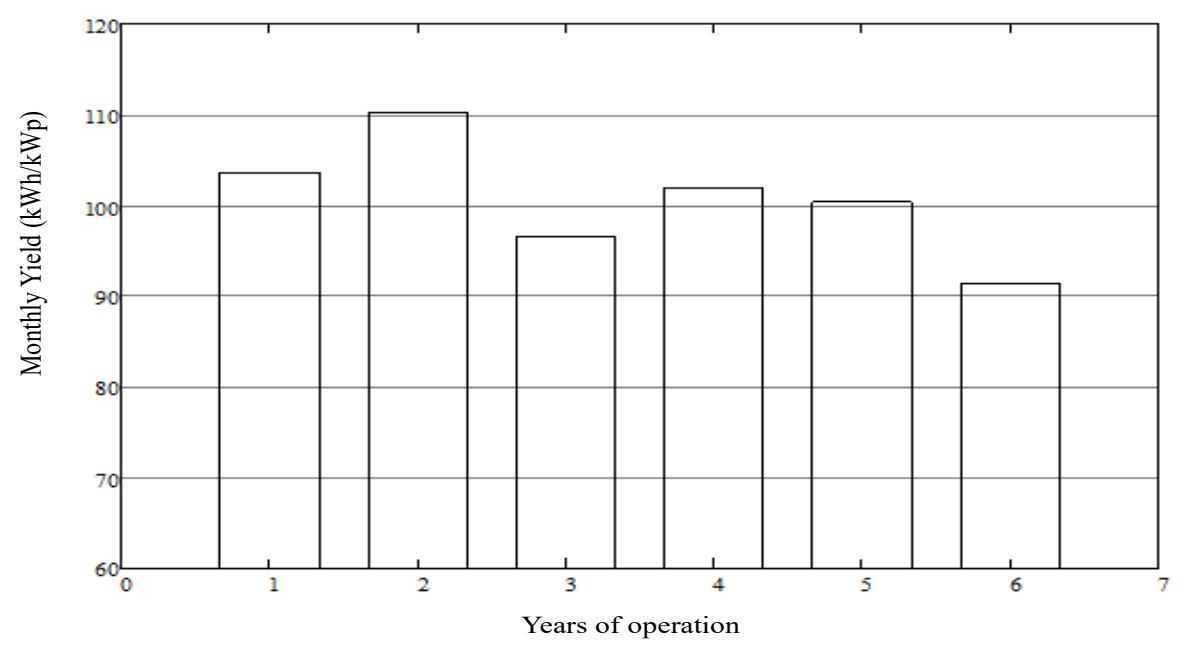

(a)

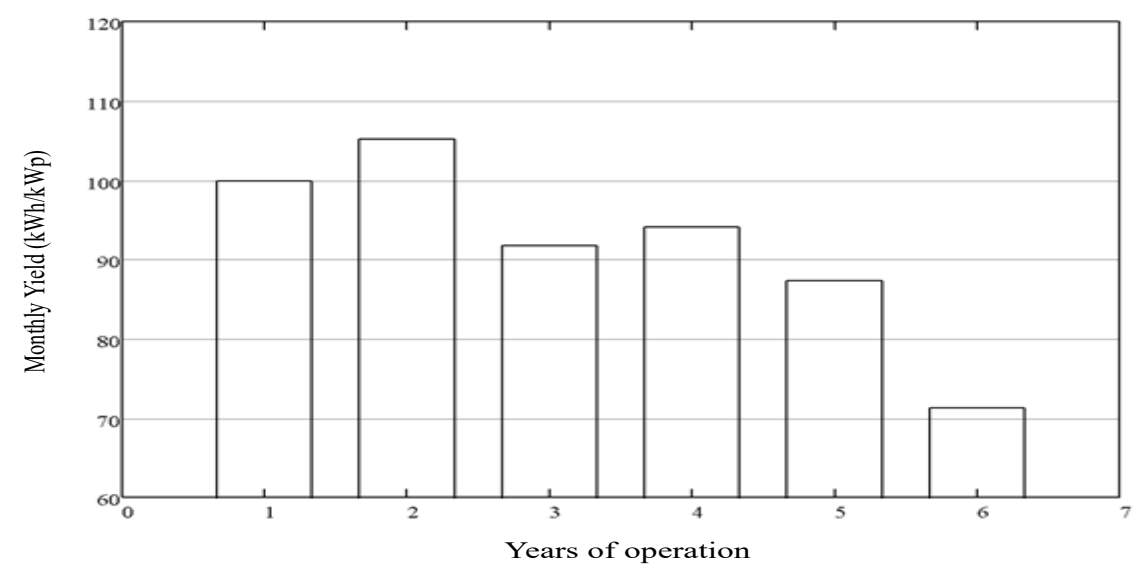

(b)

Figure 4. Final Yield (a) System A (b) System B 


\section{Performance Ratio}

The degradation of Performance Ratio (PR) during six years of operation is as depicted in Figure 5. The results revealed that the performance ratio achieved by system A for six years of operation is consistently more than $75 \%$, which is the benchmark for an accepted healthy GCPV system for Malaysia as stated in MS 2692:2020 (Department of Standards Malaysia, 2020). Meanwhile, system B shows a continuous declining trend of PR from the beginning of the operation.

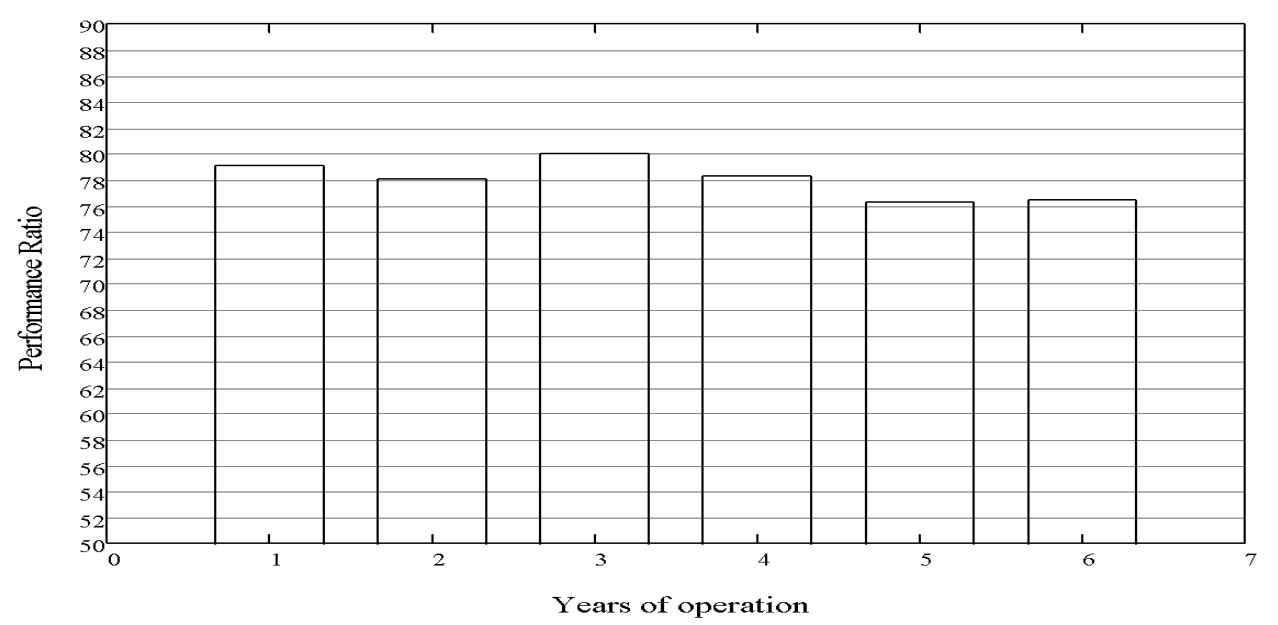

(a)

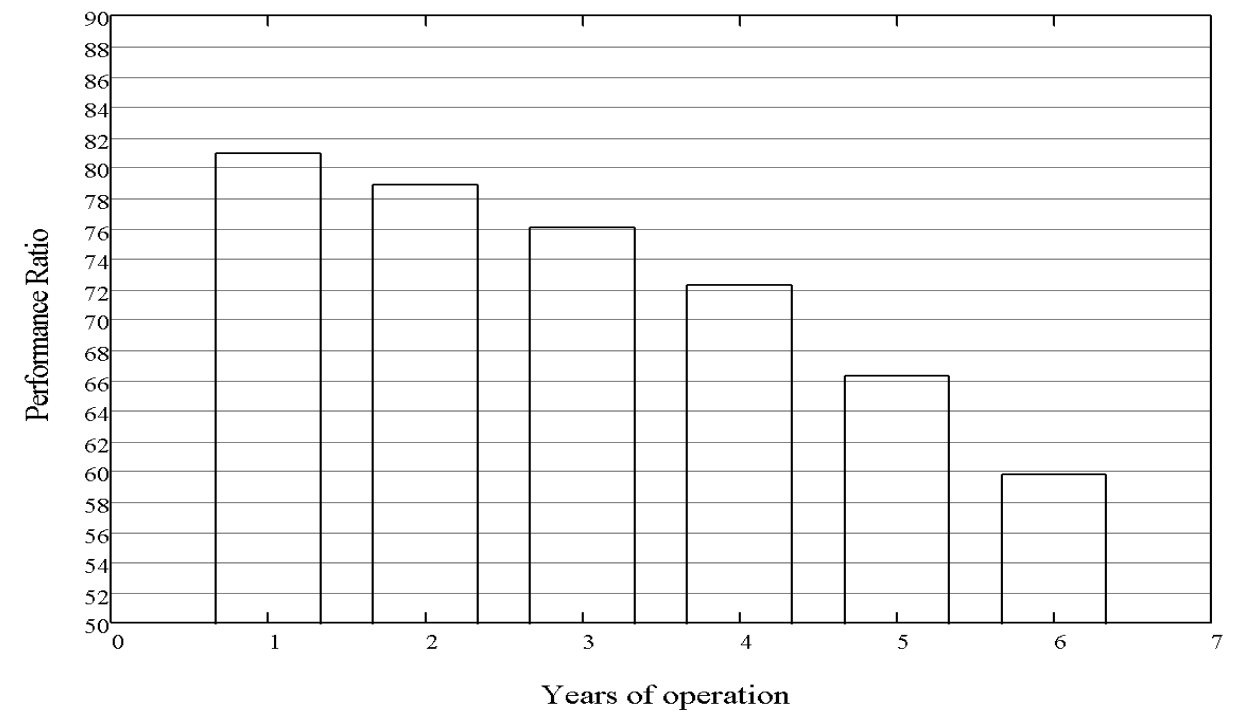

(b)

Figure 5. Performance ratio (a) System A (b) System B 


\section{CONCLUSION}

Both PV module technologies for two grid-connected PV systems under the same microclimate were monitored for over six years of operation, and performance parameters related to degradation factors were studied. Furthermore, both system performances were compared using selected parameters. From these findings, it could be concluded that system A works satisfactorily during the monitored period, while system B shows anomaly behaviour, mainly on the string voltage and marginal on the string current and other performance indices. Therefore, it is possible indications of potential-induced degradation (PID) that mostly occurs in a crystalline type of PV module technology.

The anomaly detection analysis for the GCPV system has been successfully demonstrated where the developed technique via string current and string voltage could be applied to any PV cell technology and PV system capacity. Furthermore, this technique could be used to rectify and identify the health of the GCPV system which required further detailed clarification.

\section{ACKNOWLEDGEMENTS}

The authors gratefully acknowledge the support of the Management of Universiti Teknologi MARA (UiTM) and are financially funded by the Malaysia Ministry of Education [600RMI/FRGS 5/3 (083/2019] grant. Also, thanks to the Green Energy Research Centre (GERC) for providing facilities and data in this research.

\section{REFERENCES}

Bansal, N., Pany, P., \& Singh, G. (2021). Visual degradation and performance evaluation of utility scale solar photovoltaic power plant in hot and dry climate in western India. Case Studies in Thermal Engineering, 26, Article 101010. https://doi.org/https://doi.org/10.1016/j.csite.2021.101010

Dahmoun, M. E. H., Bekkouche, B., Sudhakar, K., Guezgouz, M., Chenafi, A., \& Chaouch, A. (2021). Performance evaluation and analysis of grid-tied large scale PV plant in Algeria. Energy for Sustainable Development, 61, 181-195. https://doi.org/https://doi.org/10.1016/j.esd.2021.02.004

Department of Standards Malaysia. (2020). MS 2692:2020 Testing and commissioning of grid-connected photovoltaic system (GCPV). In Malaysian Standard (pp. 1-61). Department of Standards Malaysia.

Dubey, R., Chattopadhyay, S., Kuthanazhi, V., Kottantharayil, A., Solanki, C. S., Arora, B. M., Narasimhan, K. L., Vasi, J., Bora, B., Singh, Y. K., \& Sastry, O. S. (2017). Comprehensive study of performance degradation of field-mounted photovoltaic modules in India. Energy Science \& Engineering, 5(1), 51-64. https://doi.org/10.1002/ese3.150

Fouad, M. M., Shihata, L. A., \& Morgan, E. I. (2017). An integrated review of factors influencing the perfomance of photovoltaic panels. Renewable and Sustainable Energy Reviews, 80, 1499-1511. https://doi.org/https:// doi.org/10.1016/j.rser.2017.05.141 
Halwachs, M., Neumaier, L., Vollert, N., Maul, L., Dimitriadis, S., Voronko, Y., Eder, G. C., Omazic, A., Mühleisen, W., Hirschl, C., Schwark, M., Berger, K. A., \& Ebner, R. (2019). Statistical evaluation of PV system performance and failure data among different climate zones. Renewable Energy, 139, 1040-1060. https://doi.org/https://doi.org/10.1016/j.renene.2019.02.135

Husain, A., Phesal, M., Kadir, Z., \& Amirulddin, U. A. U. (2020). Short review on recent solar PV policies in Malaysia. E3S Web of Conferences, 191, Article 01002. https://doi.org/10.1051/e3sconf/202019101002

Hussin, M. Z., Hasliza, N., Yaacob, A., Zain, Z. M., Omar, A. M., \& Shaari, S. (2012). A development and challenges of grid-connected photovoltaic system in Malaysia. In 2012 IEEE Control and System Graduate Research Colloquium (pp. 191-196). IEEE Publishing. https://doi.org/10.1109/ICSGRC.2012.6287160

Hussin, M. Z., Shaari, S., Omar, A. M., \& Zain, Z. M. (2015). Amorphous silicon thin-film: Behaviour of light-induced degradation. Renewable and Sustainable Energy Reviews, 43, 388-402. https://doi.org/ https://doi.org/10.1016/j.rser.2014.10.093

Ishii, T., \& Masuda, A. (2017). Annual degradation rates of recent crystalline silicon photovoltaic modules. Progress in Photovoltaics: Research and Applications, 25(12), 953-967. https://doi.org/https://doi. org/10.1002/pip.2903

Islam, M. A., Hasanuzzaman, M., \& Rahim, N. A. (2018). Investigation of the potential induced degradation of on-site aged polycrystalline PV modules operating in Malaysia. Measurement, 119, 283-294. https:// doi.org/https://doi.org/10.1016/j.measurement.2018.01.061

Jamil, W. J., Rahman, H. A., Shaari, S., \& Desa, M. K. M. (2020). Modeling of soiling derating factor in determining photovoltaic outputs. IEEE Journal of Photovoltaics, 10(5), 1417-1423. https://doi. org/10.1109/JPHOTOV.2020.3003815

Jumien, N. A., Hussin, M. Z., Omar, A. M., \& Zulkapli, M. F. (2015). Performance of a 2.8 kWp monocrystalline free-standing grid-connected photovoltaic system at SIRIM berhad. In 2015 IEEE 6th Control and System Graduate Research Colloquium (ICSGRC) (pp. 93-97). IEEE Publishing. https://doi.org/10.1109/ ICSGRC.2015.7412471

Kazem, H. A., Chaichan, M. T., Al-Waeli, A. H. A., \& Sopian, K. (2020). Evaluation of aging and performance of grid-connected photovoltaic system northern Oman: Seven years' experimental study. Solar Energy, 207, 1247-1258. https://doi.org/https://doi.org/10.1016/j.solener.2020.07.061

Köntges, M., Oreski, G., Jahn, U., Herz, M., Hacke, P., Weiss, K. A., Razongles, G., Paggi, M., Parlevliet, D., \& Tanahashi, T. (2017). Assessment of photovoltaic module failures in the field. International Energy Agency.

Kunaif, K., Reinders, A., Lindig, S., Jaeger, M., \& Moser, D. (2020). Operational performance and degradation of PV systems consisting of six technologies in three climates. Applied Sciences, 10(16), Article 5412.

Lillo-Sánchez, L., López-Lara, G., Vera-Medina, J., Pérez-Aparicio, E., \& Lillo-Bravo, I. (2021). Degradation analysis of photovoltaic modules after operating for 22 years. A case study with comparisons. Solar Energy, 222, 84-94. https://doi.org/https://doi.org/10.1016/j.solener.2021.04.026

Limmanee, A., Songtrai, S., Udomdachanut, N., Kaewniyompanit, S., Sato, Y., Nakaishi, M., Kittisontirak, S., Sriprapha, K., \& Sakamoto, Y. (2017). Degradation analysis of photovoltaic modules under tropical climatic conditions and its impacts on LCOE. Renewable Energy, 102, 199-204. https://doi.org/https:// doi.org/10.1016/j.renene.2016.10.052 
Limmanee, A., Udomdachanut, N., Songtrai, S., Kaewniyompanit, S., Sato, Y., Nakaishi, M., Kittisontirak, S., Sriprapha, K., \& Sakamoto, Y. (2016). Field performance and degradation rates of different types of photovoltaic modules: A case study in Thailand. Renewable Energy, 89, 12-17. https://doi.org/https:// doi.org/10.1016/j.renene.2015.11.088

Malvoni, M., Kumar, N. M., Chopra, S. S., \& Hatziargyriou, N. (2020). Performance and degradation assessment of large-scale grid-connected solar photovoltaic power plant in tropical semi-arid environment of India. Solar Energy, 203, 101-113. https://doi.org/https://doi.org/10.1016/j.solener.2020.04.011

Malvoni, M., Leggieri, A., Maggiotto, G., Congedo, P. M., \& De Giorgi, M. G. (2017). Long term performance, losses and efficiency analysis of a $960 \mathrm{kWP}$ photovoltaic system in the Mediterranean climate. Energy Conversion and Management, 145, 169-181. https://doi.org/https://doi.org/10.1016/j. enconman.2017.04.075

Muhammad, N., Zakaria, N., Shaari, S., \& Omar, A. (2017). System performance and detectable faults of a 10-year old 1.1 kWp GCPV system in Malaysia. Science Letters, 11(1), 10-17.

Okello, D., van Dyk, E. E., \& Vorster, F. J. (2015). Analysis of measured and simulated performance data of a $3.2 \mathrm{kWp}$ grid-connected PV system in Port Elizabeth, South Africa. Energy Conversion and Management, 100, 10-15. https://doi.org/https://doi.org/10.1016/j.enconman.2015.04.064

Phinikarides, A., Kindyni, N., Makrides, G., \& Georghiou, G. E. (2014). Review of photovoltaic degradation rate methodologies. Renewable and Sustainable Energy Reviews, 40, 143-152. https://doi.org/https://doi. org/10.1016/j.rser.2014.07.155

Quansah, D. (2017). Reliability and degradation of solar PV modules - Case study of 19-year-old polycrystalline modules in Ghana. Technologies, 5(2), Article 22. https://doi.org/10.3390/technologies5020022

Roumpakias, E., \& Stamatelos, A. (2019). Performance analysis of a grid-connected photovoltaic park after 6 years of operation. Renewable Energy, 141, 368-378. https://doi.org/https://doi.org/10.1016/j. renene.2019.04.014

Saleheen, M. Z., Salema, A. A., Islam, S. M. M., Sarimuthu, C. R., \& Hasan, M. Z. (2021). A target-oriented performance assessment and model development of a grid-connected solar PV (GCPV) system for a commercial building in Malaysia. Renewable Energy, 171, 371-382. https://doi.org/https://doi. org/10.1016/j.renene.2021.02.108

SEDA. (2016). SEDA Malaysia grid-connected photovoltaic (PV) systems design course (2nd Ed.). Sustainable Energy Development Authority (SEDA) Malaysia.

Vaka, M., Walvekar, R., Rasheed, A. K., \& Khalid, M. (2020). A review on Malaysia's solar energy pathway towards carbon-neutral Malaysia beyond Covid'19 pandemic. Journal of cleaner production, 273, 122834122834. https://doi.org/10.1016/j.jclepro.2020.122834

Velautham, S., Chen, W. N., \& Han, T. W. (2019). National survey report of PV power applications in Malaysia-2019 (National Survey Reports). IEA-PVPS.

Yatim, Y., Hussin, F., Idris, M., Rahim, A., Baharudin, A., Mansur, T., \& Alhassan, S. (2014). Economical analysis of grid-connected BiPV at UNIMAP building in Kuala Perlis, Malaysia. International Journal of Renewable Energy Resources, 4(2), 42-45. 
Yatim, Y., Yahya, M. W., Tajuddin, M. F. N., Ismail, B., \& Sulaiman, S. I. (2017). Tecno-economic analysis of PV module selection for residential BIPV with net metering implementation in Malaysia. In 2017 IEEE 15th Student Conference on Research and Development (SCOReD) (pp. 361-365). IEEE Publishing. https://doi.org/10.1109/SCORED.2017.8305364

Ye, J. Y., Reindl, T., Aberle, A. G., \& Walsh, T. M. (2014). Performance degradation of various PV module technologies in tropical Singapore. IEEE Journal of Photovoltaics, 4(5), 1288-1294. https://doi. org/10.1109/JPHOTOV.2014.2338051 
